\title{
Generation of very fast states by nitridation of the $\mathrm{SiO}[2] / \mathrm{SiC}$ interface
}

\section{$\operatorname{AUTHOR}(\mathrm{S}):$}

Yoshioka, Hironori; Nakamura, Takashi; Kimoto, Tsunenobu

\section{CITATION:}

Yoshioka, Hironori ... [et al]. Generation of very fast states by nitridation of the $\mathrm{SiO}[2] / \mathrm{SiC}$ interface. Journal of Applied Physics 2012, 112(2): 024520.

\section{ISSUE DATE:}

2012-07-31

URL:

http://hdl.handle.net/2433/187958

\section{RIGHT:}

(c) 2012 American Institute of Physics. This article may be downloaded for personal use only. Any other use requires prior permission of the author and the American Institute of Physics. 


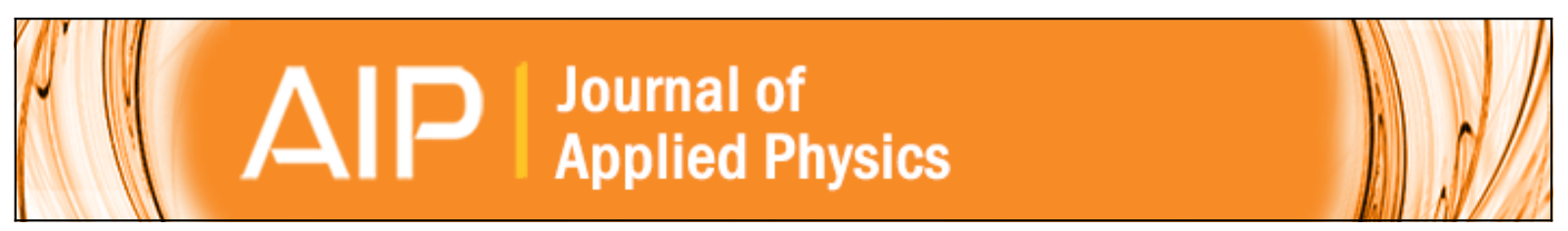

\section{Generation of very fast states by nitridation of the SiO2/SiC interface}

Hironori Yoshioka, Takashi Nakamura, and Tsunenobu Kimoto

Citation: Journal of Applied Physics 112, 024520 (2012); doi: 10.1063/1.4740068

View online: http://dx.doi.org/10.1063/1.4740068

View Table of Contents: http://scitation.aip.org/content/aip/journal/jap/112/2?ver=pdfcov

Published by the AIP Publishing

\section{Articles you may be interested in}

Modeling of high-frequency capacitance-voltage characteristics to quantify trap distributions near $\mathrm{SiO} / \mathrm{SiC}$ interfaces

J. Appl. Phys. 111, 094509 (2012); 10.1063/1.4712431

Capacitance-voltage and deep-level-transient spectroscopy characterization of defects near $\mathrm{SiO} / \mathrm{SiC}$ interfaces J. Appl. Phys. 109, 064514 (2011); 10.1063/1.3552303

Ultrashallow defect states at $\mathrm{Si} O 24 \mathrm{H}-\mathrm{Si}$ C interfaces

Appl. Phys. Lett. 92, 102112 (2008); 10.1063/1.2898502

Interface trap passivation for Si O $2\left(0001^{-}\right)$C-terminated $4 \mathrm{H}$-SiC

J. Appl. Phys. 98, 014902 (2005); 10.1063/1.1938270

Heterointerface dipoles: Applications to (a) Si-SiO 2 , (b) nitrided $\mathrm{Si}-\mathrm{N}-\mathrm{SiO} 2$, and (c) $\mathrm{SiC}-\mathrm{SiO} 2$ interfaces J. Vac. Sci. Technol. B 16, 2191 (1998); 10.1116/1.590147

\section{AlP Re-register for Table of Content Alerts}




\title{
Generation of very fast states by nitridation of the $\mathrm{SiO}_{2} / \mathrm{SiC}$ interface
}

\author{
Hironori Yoshioka, ${ }^{1}$ Takashi Nakamura, ${ }^{2}$ and Tsunenobu Kimoto ${ }^{1,3}$ \\ ${ }^{1}$ Department of Electronic Science and Engineering, Kyoto University, Kyoto 615-8510, Japan \\ ${ }^{2}$ New Material Devices R\&D Center, Rohm Co., Ltd., Kyoto 615-8585, Japan \\ ${ }^{3}$ Photonics and Electronics Science and Engineering Center, Kyoto University, Kyoto 615-8510, Japan
}

(Received 5 March 2012; accepted 2 July 2012; published online 31 July 2012)

\begin{abstract}
Fast states at $\mathrm{SiO}_{2} / \mathrm{SiC}$ interfaces annealed in $\mathrm{NO}$ at $1150-1350{ }^{\circ} \mathrm{C}$ have been investigated. The response frequency of the interface states was measured by the conductance method with a maximum frequency of $100 \mathrm{MHz}$. The interface state density was evaluated based on the difference between quasi-static and theoretical capacitances $\left(C-\psi_{\mathrm{S}}\right.$ method). Very fast states, which are not observed in as-oxidized samples, were generated by NO annealing, while states existing at an as-oxidized interface decreased by approximately $90 \%$. The response frequency of the very fast states was higher than $1 \mathrm{MHz}$ and increased when the energy level approaches the conduction band edge. For example, the response frequency (time) was $100 \mathrm{MHz}(5 \mathrm{~ns})$ at $E_{\mathrm{C}}-E_{\mathrm{T}}=0.4 \mathrm{eV}$ and room temperature. The $\mathrm{SiO}_{2} / \mathrm{SiC}$ interface annealed in $\mathrm{NO}$ at $1250^{\circ} \mathrm{C}$ showed the lowest interface state density, and NO annealing at a temperature higher than $1250{ }^{\circ} \mathrm{C}$ is not effective because of the increase in the very fast states. (C) 2012 American Institute of Physics.
\end{abstract}

[http://dx.doi.org/10.1063/1.4740068]

\section{INTRODUCTION}

Silicon carbide ( $\mathrm{SiC}$ ) has been recognized as a promising material for high-power devices, owing to its high breakdown electric field. Through recent progress in the material quality and device technology, power metal-oxide-semiconductor field effect transistors (MOSFETs) using $\mathrm{SiC}$ have been commercialized. However, SiC MOSFETs still suffer from low channel mobility. An nitridation process improves $\mathrm{SiO}_{2} / \mathrm{SiC}$ interface properties, being effective for increasing channel mobility. ${ }^{1-12}$ Although other processes such as $\mathrm{POCl}_{3}$ annealing, ${ }^{13}$ wet oxidation, ${ }^{14}$ or $\mathrm{Na}^{+}$incorporation ${ }^{15}$ also improve the mobility, nitridation is the most common process, taking reliability and stability into consideration. The channel mobility at nitrided interfaces is, however, still much lower than a value expected from bulk mobility. For example, the n-channel mobility on $4 \mathrm{H}-\mathrm{SiC}$ (0001) with nitridation is not higher than $50 \mathrm{~cm}^{2} \mathrm{~V}^{-1} \mathrm{~s}^{-1},{ }^{3-7}$ while the bulk mobility of $4 \mathrm{H}-\mathrm{SiC}$ is higher than $800 \mathrm{~cm}^{2} \mathrm{~V}^{-1} \mathrm{~s}^{-1} .16$ Therefore, it is important to reveal mobility-limiting factors at the nitrided $\mathrm{SiO}_{2} / \mathrm{SiC}$ interface and to further improve mobility by a nitridation-based process.

The interface properties have mainly been characterized in terms of interface state density $\left(D_{\mathrm{IT}}\right)$, which is conventionally evaluated by the high-low or conductance methods, because the increase in channel mobility is accompanied by decrease in interface state density. ${ }^{6-9,13}$ The interface state density is reduced with increasing $\mathrm{N}$ concentration at the interface, and the effect almost saturates at a concentration of about $5 \times 10^{14} \mathrm{~cm}^{-2} \cdot{ }^{10,11,17}$ By post-oxidation annealing in NO, which is a common nitridation method, the N concentration at the interface increases by extending the annealing time or by elevating temperature, while NO annealing at higher than $1200{ }^{\circ} \mathrm{C}$ has not been investigated in detail.

In addition to the interface state density evaluated by the conventional methods, there might exist other factors to degrade the mobility. The existence of near interface oxide traps has been suggested by other evaluation methods. ${ }^{18-20}$ The existence of fast interface states in the vicinity of the conduction band edge is also suggested by Hall-effect measurements and so on. ${ }^{9,21-24} \mathrm{We}$ proposed a method to evaluate fast interface states that can be neither detected by the conventional high-low nor conductance methods. ${ }^{25}$ By the conventional methods, fast interface states that respond to the maximum probe frequency of $0.1 \sim 1 \mathrm{MHz}$ are undetectable. The proposed $C-\psi_{\mathrm{S}}$ method can evaluate the interface state density including very fast states from the quasi-static capacitance and accurate theoretical capacitance without a frequency limit. Furthermore, for the purpose of detecting fast states, we increased the maximum probe frequency to 100 $\mathrm{MHz}$ in the high-low and conductance methods. ${ }^{25}$

The previous report ${ }^{25}$ focused on the proposal of the new evaluation methods, where a dry-oxide MOS capacitor without nitridation was employed as an example. In this study, we investigate fast states at $\mathrm{SiO}_{2} / \mathrm{SiC}$ interfaces annealed in $\mathrm{NO}$ at various temperatures using these new methods and reveal that very fast states are generated by NO annealing.

\section{EXPERIMENTS AND EVALUATION METHODS}

To fabricate MOS capacitors, a 39 47-nm-thick oxides were formed by dry oxidation at $1300{ }^{\circ} \mathrm{C}$ on n-type $4 \mathrm{H}-\mathrm{SiC}$ (0001) epilayers. The $\mathrm{SiC}$ epilayer was $7 \mu \mathrm{m}$ thick, doped with $\mathrm{N}$ to $7 \sim 9 \times 10^{15} \mathrm{~cm}^{-3}$. The thickness and resistivity of the n-type $\mathrm{SiC}$ substrate were $250 \mu \mathrm{m}$ and $0.02 \Omega \mathrm{cm}$, respectively. After oxidation, nitridation was carried out in NO $\left(10 \%\right.$ diluted in $\mathrm{N}_{2}$ ) at $1150 \sim 1350{ }^{\circ} \mathrm{C}$ (sample label: NO1150 NO1350) for $70 \mathrm{~min}$. A reference sample without NO annealing was also prepared (sample label: w/oNO). Process conditions and $\mathrm{SiO}_{2}$ thickness of the samples are summarized in Table I. The $\mathrm{SiO}_{2}$ thickness was determined 
TABLE I. Process conditions and $\mathrm{SiO}_{2}$ thickness of the samples.

\begin{tabular}{lccc}
\hline \hline Label & Oxidation & NO annealing & Thickness of $\mathrm{SiO}_{2}$ \\
\hline NO1350 & $1300^{\circ} \mathrm{C}, 32 \mathrm{~min}$ & $1350^{\circ} \mathrm{C}, 70 \mathrm{~min}$ & $41.0 \mathrm{~nm}$ \\
NO1250 & $1300^{\circ} \mathrm{C}, 32 \mathrm{~min}$ & $1250^{\circ} \mathrm{C}, 70 \mathrm{~min}$ & $39.0 \mathrm{~nm}$ \\
NO1150 & $1300^{\circ} \mathrm{C}, 40 \mathrm{~min}$ & $1150^{\circ} \mathrm{C}, 70 \mathrm{~min}$ & $47.3 \mathrm{~nm}$ \\
w/oNO & $1300^{\circ} \mathrm{C}, 32 \mathrm{~min}$ & - & $39.1 \mathrm{~nm}$ \\
\hline
\end{tabular}

from the accumulation capacitance in $C-V$ measurements, where a relative dielectric constant of 3.9 was employed. Circular Ni electrodes (gate) with a diameter of $0.6 \sim 0.7 \mathrm{~mm}$ were deposited on the sample surface.

According to Ref. 25, the quasi-static capacitance and impedance were measured, and interface properties were evaluated. Details of measurement conditions and analytical procedures are described in Ref. 25. The quasi-static capacitance $\left(C_{\mathrm{QS}}\right)$ was measured by Quasistatic CV Meter (595, Keithley), and the impedance was measured by Precision Impedance Analyzer (4294 A, Agilent Technologies) with a probe kit (42941 A, Agilent Technologies). The relationship between the gate voltage and surface potential $\left(\psi_{\mathrm{S}}\right)$ is determined by ${ }^{25,26}$

$$
\psi_{\mathrm{S}}\left(V_{\mathrm{G}}\right)=\int\left(1-C_{\mathrm{QS}} / C_{\mathrm{OX}}\right) d V_{\mathrm{G}}+A,
$$

where the integration constant $(A)$ is determined based on the depletion capacitance. ${ }^{25}$ The surface potential is used to calculate the theoretical semiconductor capacitance $\left(C_{\mathrm{D} \text {,theory }}\right)$ and Fermi level at the interface $\left(E_{\mathrm{C}}-E_{\mathrm{F}}\right)$. The sum $\left(C_{\mathrm{D}}+\right.$ $\left.C_{\mathrm{IT}}\right)$ of semiconductor capacitance $\left(C_{\mathrm{D}}\right)$ and interface-state capacitance $\left(C_{\mathrm{IT}}\right)$ is extracted from the measured impedance and quasi-static capacitance. In the $C-\psi_{\mathrm{s}}$ method, the interface state density is given by ${ }^{25}$

$$
\begin{gathered}
D_{\mathrm{IT}}\left(C-\psi_{\mathrm{S}}\right)=\frac{\left(C_{\mathrm{D}}+C_{\mathrm{IT}}\right)_{\mathrm{QS}}-C_{\mathrm{D}, \text { theory }}}{S e^{2}}, \\
C_{\mathrm{D}, \text { theory }}\left(\psi_{\mathrm{S}}\right)=\frac{S e N_{\mathrm{D}}\left|\exp \left(\frac{e \psi_{\mathrm{S}}}{k T}\right)-1\right|}{\sqrt{\frac{2 k T N_{\mathrm{D}}}{\varepsilon_{\mathrm{SiC}}}\left\{\exp \left(\frac{e \psi_{\mathrm{S}}}{k T}\right)-\frac{e \psi_{\mathrm{S}}}{k T}-1\right\}}},
\end{gathered}
$$

where $\left(C_{\mathrm{D}}+C_{\mathrm{IT}}\right)_{\mathrm{QS}}$ is the $C_{\mathrm{D}}+C_{\mathrm{IT}}$ extracted from the quasistatic capacitance, $S$ is the area of the gate electrode, $\varepsilon_{\mathrm{SiC}}$ $\left(9.7 \varepsilon_{0}\right)$ is the dielectric constant of $\mathrm{SiC}$, and $N_{\mathrm{D}}$ is the donor concentration of the $\mathrm{SiC}$ epilayer. For the high-low method, the interface state density is given by ${ }^{25,26}$

$$
D_{\mathrm{IT}}(\text { high }- \text { low })=\frac{\left(C_{\mathrm{D}}+C_{\mathrm{IT}}\right)_{\mathrm{QS}}-\left(C_{\mathrm{D}}+C_{\mathrm{IT}}\right)_{\mathrm{HF}}}{S e^{2}},
$$

where $\left(C_{\mathrm{D}}+C_{\mathrm{IT}}\right)_{\mathrm{HF}}$ is the $C_{\mathrm{D}}+C_{\mathrm{IT}}$ extracted from impedance measured at $1 \mathrm{MHz}\left(\right.$ high $_{1 \mathrm{M}}-$ low) or $100 \mathrm{MHz}$ $\left(\right.$ high $_{100 \mathrm{M}}-$ low).

As a rough approximation, the interface states responding to lower than $1 \mathrm{MHz}$ are detected by the $\operatorname{high}_{1 \mathrm{M}}-$ low method, the states responding to lower than $100 \mathrm{MHz}$ are detected by the high ${ }_{100 \mathrm{M}}$-low method, and all the states are detected by the $C-\psi_{\mathrm{s}}$ method. Thus, the density of interface states responding to a certain frequency range can be roughly estimated by

$$
\begin{gathered}
D_{\mathrm{IT},<1 \mathrm{M}}=D_{\mathrm{IT}}\left(\text { high }_{1 \mathrm{M}}-\text { low }\right), \\
D_{\mathrm{IT}, 1 \mathrm{M} \sim 100 \mathrm{M}}=D_{\mathrm{IT}}\left(\text { high }_{100 \mathrm{M}}-\text { low }\right)-D_{\mathrm{IT}}\left(\text { high }_{1 \mathrm{M}}-\text { low }\right),
\end{gathered}
$$

$$
\begin{gathered}
D_{\mathrm{IT}, 100 \mathrm{M}<}=D_{\mathrm{IT}}\left(C-\psi_{\mathrm{S}}\right)-D_{\mathrm{IT}}\left(\text { high }_{100 \mathrm{M}}-\text { low }\right), \\
D_{\mathrm{IT}, \text { all }}=D_{\mathrm{IT}}\left(C-\psi_{\mathrm{S}}\right),
\end{gathered}
$$

where $D_{\mathrm{IT},<1 \mathrm{M}}, D_{\mathrm{IT}, 1 \mathrm{M} \sim 100 \mathrm{M}}$, and $D_{\mathrm{IT}, 100 \mathrm{M}<}$ are the densities of interface states responding to a frequency $(f)$ range of $f<1 \mathrm{MHz}, 1 \mathrm{MHz}<f<100 \mathrm{MHz}$, and $100 \mathrm{MHz}<f$, respectively, and $D_{\mathrm{IT} \text {,all }}$ is the total interface state density.

The interface-state conductance $\left(G_{\mathrm{PIT}}\right)$ is extracted from the measured impedance. In the conductance method, the interface state density is directly linked to $G_{\mathrm{PIT}}$ by $^{25,26}$

$$
\begin{aligned}
G_{\mathrm{PIT}} / \omega= & e^{2} S D_{\mathrm{IT}}(\text { conductance }) \int_{-\infty}^{+\infty} \frac{\ln \left(1+(\omega \tau \exp (\eta))^{2}\right)}{2 \omega \tau \exp (\eta)} \\
& \times \frac{1}{\sqrt{2 \pi \sigma^{2}}} \exp \left(-\frac{\eta^{2}}{2 \sigma^{2}}\right) d \eta
\end{aligned}
$$

where $\omega$ is the angular frequency. The interface state density $\left(D_{\mathrm{IT}}\right)$, the time constant of the interface states $(\tau)$, and the standard deviation $(\sigma)$ are determined by fitting experimental results with this equation. The capture cross section $\left(\sigma_{\mathrm{C}}\right)$ is given by ${ }^{27}$

$$
\sigma_{\mathrm{C}}=\frac{1}{\tau v_{\mathrm{th}} N_{\mathrm{C}}} \exp \left(\frac{E_{\mathrm{C}}-E_{\mathrm{T}}}{k T}\right)
$$

where $v_{\text {th }}\left(1.8 \times 10^{7} \mathrm{~cm} / \mathrm{s}\right)$ is the thermal velocity of electrons, and $N_{\mathrm{C}}\left(1.8 \times 10^{19} \mathrm{~cm}^{-3}\right)$ is the effective density of states in the conduction band.

The profile of $\mathrm{N}$ atoms near the interface was measured by secondary ion mass spectrometry (SIMS), where primary ions of $\mathrm{Cs}^{+}$with $5 \mathrm{keV}$ and secondary ions of $\mathrm{CsN}^{+}$were employed. The $\mathrm{N}$ concentration was determined based on signals from standard $\mathrm{SiO}_{2} / \mathrm{SiC}$ samples implanted with $\mathrm{N}$ atoms.

\section{RESULTS AND DISCUSSION}

Figure 1 shows interface-state conductances $\left(G_{\mathrm{PIT}}\right)$ at different gate voltages for samples w/oNO and NO1350, where some of calculated energy levels $\left(E_{\mathrm{C}}-E_{\mathrm{F}}\right)$ at the interface are indicated instead of gate voltage. Two distinct peaks (OX' and NI) were observed for sample NO1350, while a broad single peak (OX) was observed for the sample without NO annealing. The intensity and the frequency of peaks OX, $\mathrm{OX}^{\prime}$, and NI increased when the energy level approaches the conduction band edge. Peak NI takes a maximum at a frequency higher than $1 \mathrm{MHz}$, and the peak moves out of the measurable frequency range for $E_{\mathrm{C}}-E_{\mathrm{F}}<0.4 \mathrm{eV}$.

Figure 2 shows the $G_{\text {PIT }}$ for the samples annealed in NO at different temperatures. Peak OX significantly decreased 


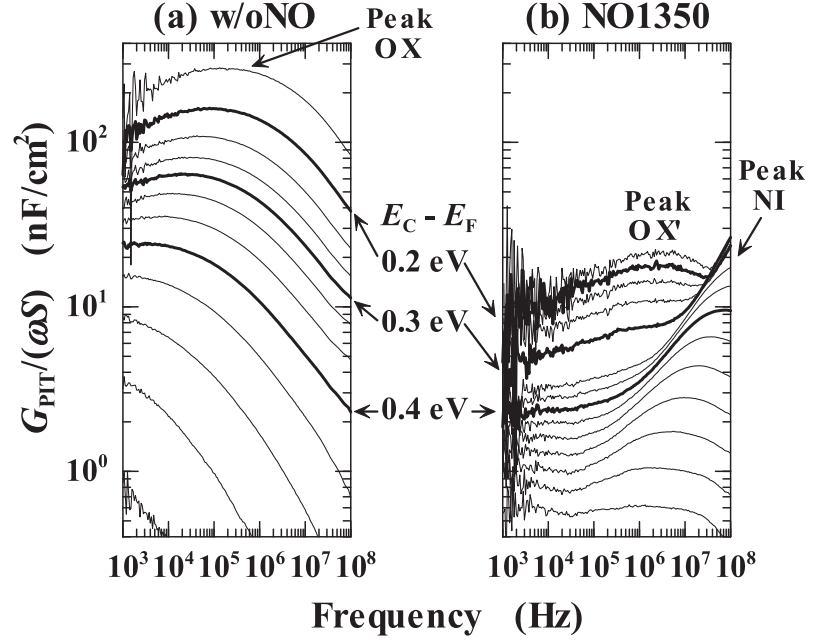

FIG. 1. Interface-state conductance $\left(G_{\mathrm{PIT}}\right)$ normalized by angular frequency $(\omega)$ and area $(S)$ at different gate voltages for samples (a) w/oNO and (b) NO1350, where some of calculated energy levels $\left(E_{\mathrm{C}}-E_{\mathrm{F}}\right)$ at the interface are indicated with bold lines.

by $\mathrm{NO}$ annealing, and peak $\mathrm{OX}^{\prime}$ would be a remnant of peak OX. The intensity of peak NI increased with increasing the NO-annealing temperature, while peak NI was not observed for the sample without NO annealing, indicating that peak $\mathrm{NI}$ is generated by NO annealing. Although the interfacestate conductance in nitrided $\mathrm{SiC}$ MOS capacitors has been previously measured, ${ }^{28}$ only peak $\mathrm{OX}$ or $\mathrm{OX}^{\prime}$ was detected. Since the maximum probe frequency was $1 \mathrm{MHz}$ in the previous report, peak NI must appear out of the measured frequency range even if the interface states related to peak NI exist. Furthermore, the NO-annealing temperature was limited to $1100{ }^{\circ} \mathrm{C}$ in the previous report. Therefore, peak NI must be small, as seen in Fig. 2. In other words, peak NI can be detected by measurement at a sufficiently high frequency in MOS structures annealed in NO at high temperature. Since the response of peak NI is very fast, the conventional highlow and conductance methods with the maximum frequency of $0.1 \sim 1 \mathrm{MHz}$ cannot detect peak NI. Even though the maximum frequency is $100 \mathrm{MHz}$, only a part of peak NI can be detected even at relatively deep energy levels (Figs. 2(b) and

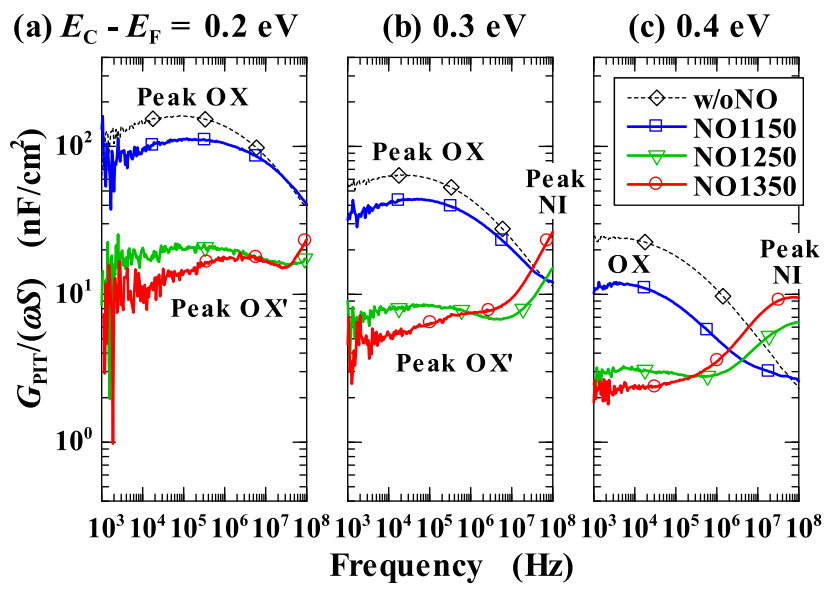

FIG. 2. Interface-state conductance $\left(G_{\mathrm{PIT}}\right)$ normalized by angular frequency $(\omega)$ and area $(S)$ at $E_{\mathrm{C}}-E_{\mathrm{F}}$ of (a) $0.2 \mathrm{eV}$, (b) $0.3 \mathrm{eV}$, and (c) $0.4 \mathrm{eV}$ for samples annealed in $\mathrm{NO}$ at different temperatures. 2(c)), which makes it difficult to evaluate the interface state density correctly by the high-low and conductance methods. On the other hand, the $C-\psi_{\mathrm{S}}$ method can accurately evaluate interface state density including fast states. ${ }^{25}$

Figure 3 shows the interface state densities for samples (a) w/oNO and (b) NO1350 evaluated by the $C-\psi_{\mathrm{S}}$ method (label: $C-\psi_{\mathrm{S}}$ ), the high-low methods using high frequencies of $1 \mathrm{MHz}$ and $100 \mathrm{MHz}$ (high $\mathrm{M}_{\mathrm{M}}$-low and high $\mathrm{Ho0M}^{-}$low) and the conductance method (conductance). As for the interface state density determined by the conductance method of sample NO1350, $G_{\mathrm{PIT}} / \omega$ mainly consisted of peak $\mathrm{OX}^{\prime}$ for $E_{\mathrm{C}}-E_{\mathrm{T}}<0.3 \mathrm{eV}$, and the interface state density of peak $\mathrm{OX}^{\prime}$ is plotted in Fig. 3(b) with circular symbols. On the other hand, $G_{\mathrm{PIT}} / \omega$ mainly consisted of peak NI for $E_{\mathrm{C}}-E_{\mathrm{T}}>$ $0.4 \mathrm{eV}$, and the interface state density of peak NI is shown with triangular symbols. For samples annealed in NO, there exists a substantial difference in interface state densities obtained by different methods. For example, the interface state density evaluated by the high $100 \mathrm{M}-$ low method is similar to that by the conductance method, but it is higher than that by the high $\mathrm{M}_{\mathrm{M}}$-low method and is considerably lower than that by the $C-\psi_{\mathrm{S}}$ method, especially near the conduction band edge. These discrepancies can be explained by the different maximum frequency of detection by the methods.

Figures 4(a)-4(d) show $D_{\mathrm{IT},<1 \mathrm{M}}, D_{\mathrm{IT}, 1 \mathrm{M} \sim 100 \mathrm{M}}, D_{\mathrm{IT}, 100 \mathrm{M}<}$, and $D_{\text {IT,all }}$ estimated from Eqs. (5)-(8), respectively, for
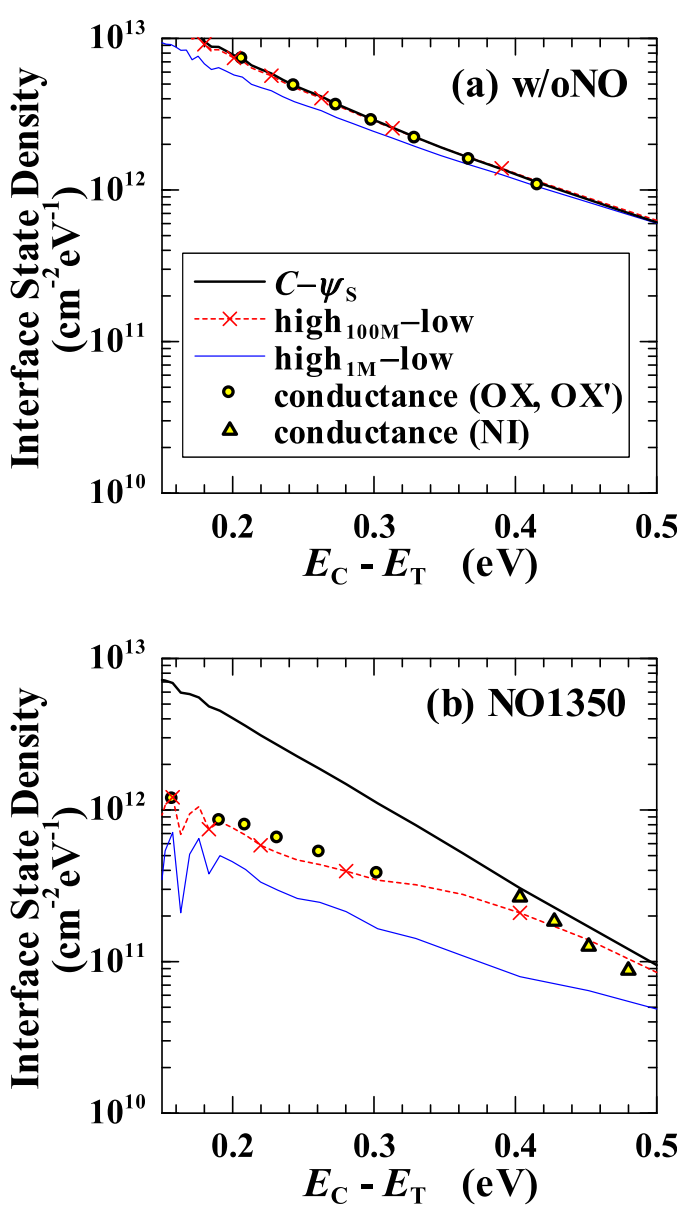

FIG. 3. Interface state densities evaluated by various methods for the samples (a) w/oNO and (b) NO1350. 


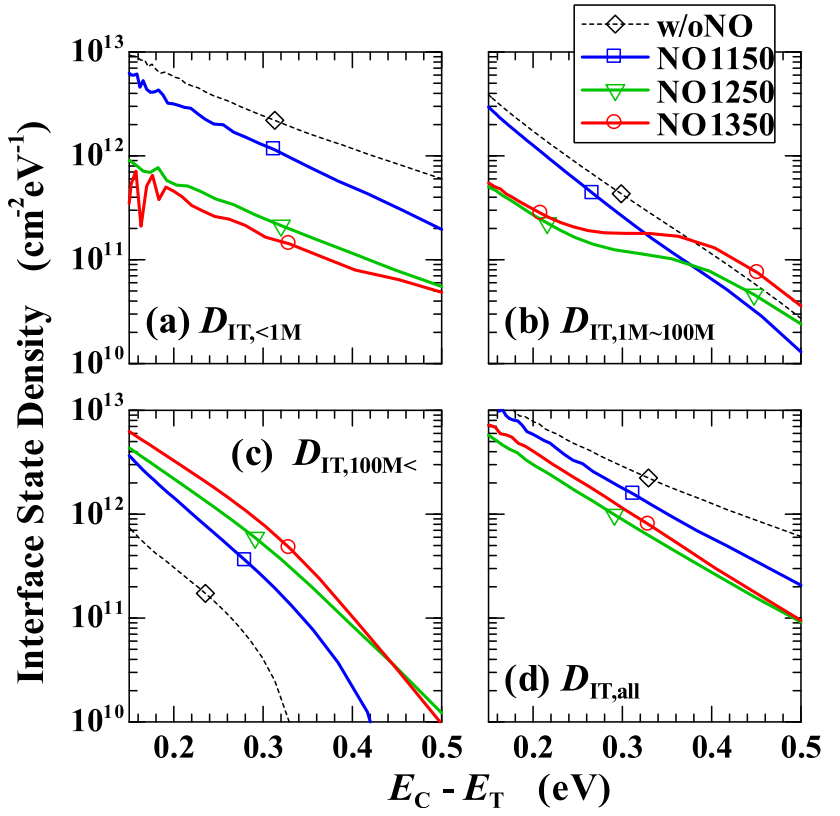

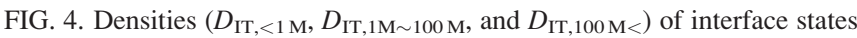
responding to a frequency range of (a) $f<1 \mathrm{MHz}$, (b) $1 \mathrm{MHz}<f<$ $100 \mathrm{MHz}$, and (c) $100 \mathrm{MHz}<f$, respectively, and (d) total interface state density $\left(D_{\mathrm{IT}, a l l}\right)$ for samples annealed in NO at different temperatures.

the samples annealed in $\mathrm{NO}$ at different temperatures. The $D_{\mathrm{IT},<1 \mathrm{M}}$ decreased by approximately $90 \%$ for the samples annealed at higher than $1250^{\circ} \mathrm{C}$, compared with the nonnitrided sample (Fig. 4(a)). NO annealing at higher temperature was more effective to reduce the relatively slow interface states. Because $D_{\mathrm{IT},<1 \mathrm{M}}$ mainly originates from peak $\mathrm{OX}$ or $\mathrm{OX}^{\prime}$, interface states OX can be effectively decreased by NO annealing. The $D_{\mathrm{IT},<1 \mathrm{M}}$ is equivalent to $D_{\mathrm{IT}}\left(\right.$ high $_{1 \mathrm{M}}-$ low $)$ (Eq. (5)) and reduction of the interface state density by nitridation is a well-known result as far as the high-low method is employed. $^{6-13}$ The $D_{\mathrm{IT}, 1 \mathrm{M} \sim 100 \mathrm{M}}$ for $E_{\mathrm{C}}-E_{\mathrm{T}}>0.3 \mathrm{eV}$ increased by $\mathrm{NO}$ annealing, while $D_{\mathrm{IT}, 1 \mathrm{M} \sim 100 \mathrm{M}}$ for $E_{\mathrm{C}}-E_{\mathrm{T}}<$ $0.3 \mathrm{eV}$ decreased (Fig. 4(b)). For $E_{\mathrm{C}}-E_{\mathrm{T}}>0.3 \mathrm{eV}$ and $1 \mathrm{MHz}<f<100 \mathrm{MHz}$, a large part of the interface-state conductance consists of peak NI (Fig. 2(c)), and the increase in interface states NI by NO annealing is responsible for the increase in $D_{\mathrm{IT}, 1 \mathrm{M} \sim 100 \mathrm{M}}$. On the other hand, for $E_{\mathrm{C}}-E_{\mathrm{T}}<$ $0.3 \mathrm{eV}$ and $1 \mathrm{MHz}<f<100 \mathrm{MHz}$, a large part of the conductance consists of peaks OX or OX' (Fig. 2(a)). Thus, the decrease in interface states $\mathrm{OX}$ or $\mathrm{OX}^{\prime}$ by $\mathrm{NO}$ annealing is responsible for the decrease in $D_{\mathrm{IT}, 1 \mathrm{M} \sim 100 \mathrm{M}}$. The $D_{\mathrm{IT}, 100 \mathrm{M}<}$ increased with elevating NO-annealing temperature (Fig. 4(c)). Although peak NI of the interface-state conductance cannot be measured for more than $100 \mathrm{MHz}$ (Figs. 1 and 2), the increase in $D_{\mathrm{IT}, 100 \mathrm{M}<}$ indicates that very fast states NI responding to more than $100 \mathrm{MHz}$ increase by $\mathrm{NO}$ annealing. The total interface state density $\left(D_{\mathrm{IT}, a l l}\right)$ was reduced by NO annealing (Fig. 4(d)). It should be noted that sample NO1250 exhibited the lowest $D_{\text {IT,all }}$. NO annealing at a temperature higher than $1250{ }^{\circ} \mathrm{C}$ is not effective because of the increase in very fast states NI.

Figures 5(a) and 5(b) represents the time constants $(\tau)$ and capture cross sections $\left(\sigma_{\mathrm{C}}\right)$, respectively, of the interface states $\left(\mathrm{OX}, \mathrm{OX}^{\prime}\right.$, and $\left.\mathrm{NI}\right)$, which were determined by using
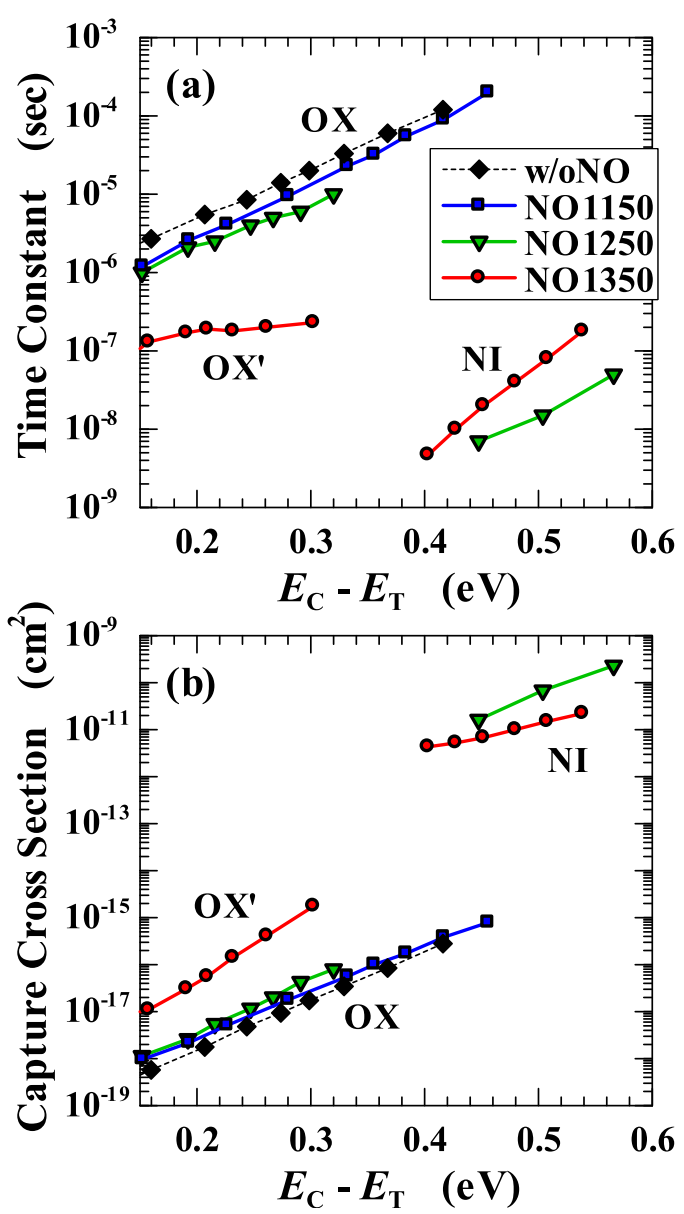

FIG. 5. (a) Time constants and (b) capture cross sections of peaks $\mathrm{OX}, \mathrm{OX}^{\prime}$ and NI obtained by the conductance method for samples annealed in NO at different temperatures.

Eqs. (9) and (10) from the interface-state conductance (Figs. 1 and 2). In general, the charge state of interface states can be speculated from the magnitude of capture cross section. Donor-type states change from positive to neutral in the charge state by capturing electrons and have a large capture cross section. Acceptor-type states change from neutral to negative by capturing electrons and have a smaller capture cross section. Interface states NI possess a very large capture cross section in the range of $10^{-12} \sim 10^{-10} \mathrm{~cm}^{2}$, indicating that interface states NI may be donor type. Such a large capture cross section has not been reported so far. On the other hand, interface states $\mathrm{OX}$ and $\mathrm{OX}^{\prime}$ possess much smaller capture cross sections in the range of $10^{-19} \sim 10^{-15} \mathrm{~cm}^{2}$, which is comparable to earlier reports, ${ }^{28,29}$ and may be acceptor type. A possible origin of interface states NI might be N-related donor-like states as in bulk $\mathrm{SiC}^{30-33}$ Umeda et al. investigated $\mathrm{SiC}$ MOS structures by electrically detected magnetic resonance (EDMR) spectroscopy and detected a peculiar EDMR signal, which was only observed in the nitrided $\mathrm{SiO}_{2} / \mathrm{SiC}$ structure. ${ }^{34}$ They suggested that the observed signal was similar to that of $\mathrm{N}$ donors in bulk $\mathrm{SiC}$. A high concentration of $\mathrm{N}$ atoms at the interface would slightly diffuse into the bulk $\mathrm{SiC}$, although the diffusion coefficient of $\mathrm{N}$ atoms in $\mathrm{SiC}$ is very small. ${ }^{35}$ The N-related states may energetically spread below the conduction-band 
edge, because of the high concentration and possible disorder of the crystal near the interface.

Figure 6(a) shows the depth profile of $\mathrm{N}$ atom concentration measured by SIMS for the samples annealed in NO at different temperatures, where the peak (interface) position is set as the origin of the horizontal axis. As in earlier reports, ${ }^{6,11,12,17,36}$ the depth profile of $\mathrm{N}$ atoms for the samples annealed in NO exhibited a distinct peak at the interface. The $\mathrm{N}$ concentration increased when NO-annealing temperature was elevated. The $\mathrm{N}$ peak of sample NO1350 was almost the same as that of sample NO1250, while the width was slightly broader. In other words, the interface is almost saturated with $\mathrm{N}$ atoms by $\mathrm{NO}$ annealing at about $1250^{\circ} \mathrm{C}$, and a further raise in NO-annealing temperature only results in additional $\mathrm{N}$ diffusion into $\mathrm{SiC}$ and $\mathrm{SiO}_{2}$. Figure 6(b) shows the dependence of $D_{\mathrm{IT},<1 \mathrm{M}}, D_{\mathrm{IT}, 100 \mathrm{M}<\text {, and } D_{\mathrm{IT}, \text { all }} \text { at }}$ $E_{\mathrm{C}}-E_{\mathrm{T}}=0.3 \mathrm{eV}$ on the area concentration of $\mathrm{N}$ atoms calculated from the SIMS profiles. The density of slow states $\left(D_{\mathrm{IT},<1 \mathrm{M}}\right)$, which is mainly composed of interface states OX or $\mathrm{OX}^{\prime}$, decreased with increasing the $\mathrm{N}$ area concentration. On the other hand, the density of very fast states $\left(D_{\mathrm{IT}, 100 \mathrm{M}<}\right)$, which is mainly composed of states NI, increased almost in proportion to the $\mathrm{N}$ area concentration. This is another evidence that the very fast states are linked to interface nitridation. As a result, the total interface state density
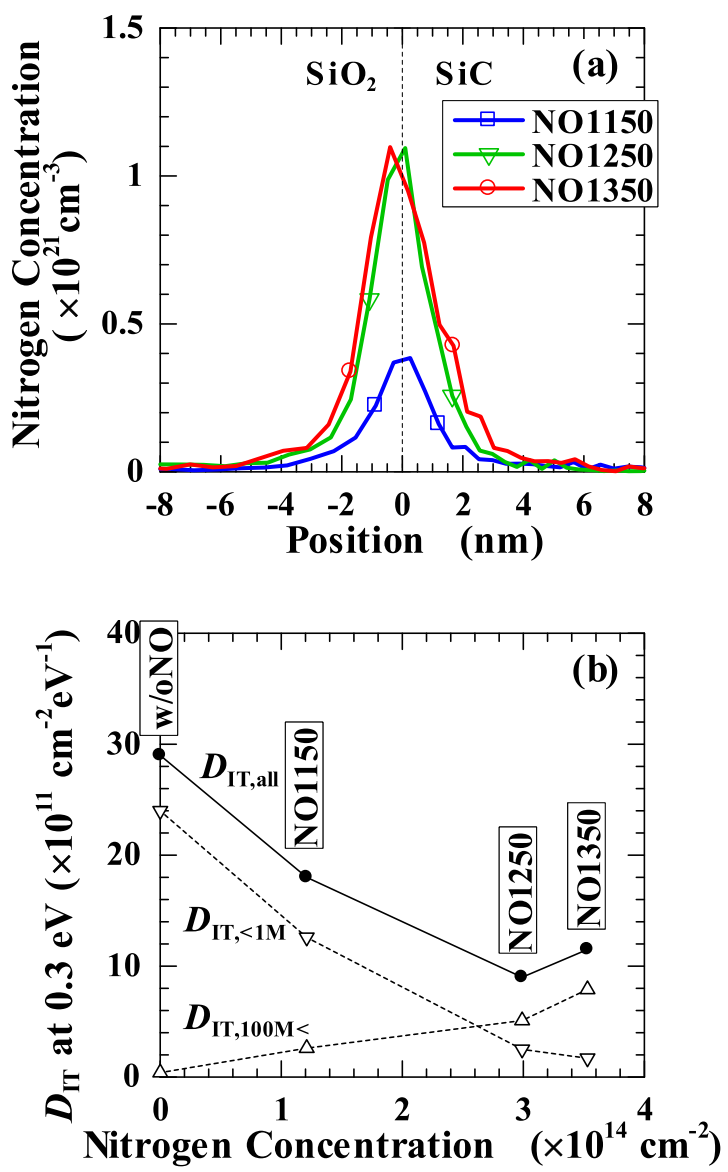

FIG. 6. (a) Depth profiles of $\mathrm{N}$ atom concentration measured by SIMS for the samples annealed in NO at different temperatures, where the peak (interface) position is set as the origin of the horizontal axis. (b) The dependence of $D_{\mathrm{IT},<1 \mathrm{M}}, D_{\mathrm{IT}, 100 \mathrm{M}<}$, and $D_{\mathrm{IT}, \text { all }}$ at $E_{\mathrm{C}}-E_{\mathrm{T}}=0.3 \mathrm{eV}$ on the area concentration of $\mathrm{N}$ atoms.
$\left(D_{\text {IT,all }}\right)$ showed a minimum at an $\mathrm{N}$ area concentration of $3.0 \times 10^{14} \mathrm{~cm}^{-2}$ (NO1250).

As discussed above, the high-low method severely underestimates the interface state density when fast interface states respond to the probe frequency in the high-frequency measurements. Since the response frequency of interface states decreases with lowering temperature, interface states cannot respond to the high probe frequency at a sufficiently low temperature. In this case, the high-frequency capacitance should agree with the ideal capacitance without a contribution of interface state capacitance, and the high-low method should give the same interface state density as the $C-\psi_{\mathrm{S}}$ method. Thus, at sufficiently low temperature, the density of very fast states NI can be evaluated even by the conventional high $_{1 \mathrm{M}}$-low method as well as the $C-\psi_{\mathrm{S}}$ method.

Figure 7 shows the interface state densities for sample NO1350 evaluated by the $C-\psi_{\mathrm{S}}$ and high ${ }_{1 \mathrm{M}}$-low methods at different measurement temperatures. At $100 \mathrm{~K}$, the interface state density obtained by the high $\mathrm{MM}$-low method agreed very well with that by the $C-\psi_{\mathrm{S}}$ method, as expected. This result proves that the response frequencies of all the interface states including states NI decrease to less than $1 \mathrm{MHz}$ at $100 \mathrm{~K}$ and the measured high-frequency capacitance agrees with the theoretical capacitance. When we look at the temperature dependence in detail, with lowering the measurement temperature from 300 to $100 \mathrm{~K}$, the interface state density obtained by the high $\mathrm{M}_{\mathrm{M}}$-low method gradually approaches that by the $C-\psi_{\mathrm{S}}$ method from the deep energy levels toward the shallow levels. In general, the time constants of the interface states are longer at deeper energy levels (Fig. 5(a)). When the measurement temperature is lowered from $300 \mathrm{~K}$, the fast interface states become unresponsive to $1 \mathrm{MHz}$ from deep energy levels and become detectable by the high ${ }_{1 \mathrm{M}}$-low method.

The interface state density determined by the $C-\psi_{\mathrm{S}}$ method did not change with the measurement temperature very much from 300 to $150 \mathrm{~K}$ but remarkably decreased when the temperature was decreased to $100 \mathrm{~K}$. At such a low temperature of $100 \mathrm{~K}$, most slow states will be frozen and

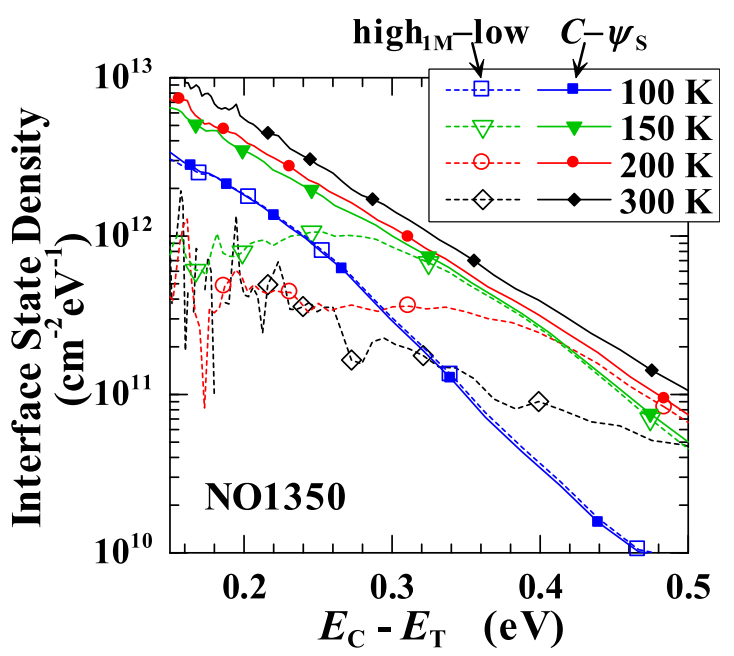

FIG. 7. Interface state densities of sample NO1350 evaluated by the $C-\psi_{\mathrm{S}}$ (solid line) and high ${ }_{1 \mathrm{M}}$-low (broken line) methods at different measurement temperatures. 
behave like interface fixed charges. These slow states do not contribute to the quasi-static capacitance at $100 \mathrm{~K}$ or lower. Thus, the high ${ }_{1 \mathrm{M}}$-low method as well as the $C-\psi_{\mathrm{S}}$ method underestimates the slow states at $100 \mathrm{~K}$, because the two methods employ the same quasi-static capacitance to determine interface state density. In other words, the high $\mathrm{M}^{-}$low method cannot correctly determine interface state density at any measurement temperatures due to the underestimation of fast states near room temperature and the underestimation of slow states at low temperature. On the other hand, the $C-\psi_{\mathrm{S}}$ method can correctly evaluate interface state density including fast states near room temperature.

\section{CONCLUSION}

We have investigated the $\mathrm{SiO}_{2} / \mathrm{SiC}$ interfaces annealed in $\mathrm{NO}$ at various temperature by the $C-\psi_{\mathrm{S}}$ and conductance methods and revealed that very fast states (NI) are generated by NO annealing. The response frequency of states NI was $100 \mathrm{MHz}$ or higher at room temperature. The conventional high-low and conductance methods with the maximum probe frequency of $0.1 \sim 1 \mathrm{MHz}$ cannot detect fast states NI. Although the interface states (OX) existing at an as-oxidized interface decreased by approximately $90 \%$ by NO annealing, a large part of the reduction was canceled by the generation of fast states NI. This may be a reason why the channel mobility has been limited to about $50 \mathrm{~cm}^{2} \mathrm{~V}^{-1} \mathrm{~s}^{-1}$, in spite of the remarkable reduction in the interface state density evaluated by the conventional high-low method. The density of fast states NI increased with elevation the NO-annealing temperature and is proportional to the area concentration of $\mathrm{N}$ atoms near the interface. Interface states NI would be of donor-like nature, taking account of the very fast response and large capture cross section $\left(\sim 10^{-11} \mathrm{~cm}^{2}\right)$.

${ }^{1}$ H. Li, S. Dimitrijev, H. B. Harrison, and D. Sweatman, Appl. Phys. Lett. 70, 2028 (1997).

${ }^{2}$ G. Y. Chung, C. C. Tin, J. R. Williams, K. McDonald, R. K. Chanana, R. A. Weller, S. T. Pantelides, L. C. Feldman, O. W. Holland, M. K. Das, and J. W. Palmour, IEEE Electron Device Lett. 22, 176 (2001).

${ }^{3}$ R. Schörner, P. Friedrichs, D. Peters, D. Stephani, S. Dimitrijev, and P. Jamet, Appl. Phys. Lett. 80, 4253 (2002).

${ }^{4}$ C.-Y. Lu, J. A. Cooper, Jr., T. Tsuji, G. Chung, J. R. Wiliams, K. McDonald, and L. C. Feldman, IEEE Trans. Electron Devices 50, 1582 (2003).

${ }^{5}$ X. Zhu, A. C. Ahyi, M. Li, Z. Chen, J. Rozen, L. C. Feldman, and J. R. Williams, Solid-State Electron. 57, 76 (2011).

${ }^{6}$ K. Fujihira, Y. Tarui, M. Imaizumi, K. Ohtsuka, T. Takami, T. Shiramizu, K. Kawase, J. Tanimura, and T. Ozeki, Solid-State Electron. 49, 896 (2005). ${ }^{7}$ S. Dhar, S. Wang, J. R.Williams, S. T. Pantelides, and L. C. Feldman, MRS Bull. 30, 288 (2005).
${ }^{8}$ M. Noborio, J. Suda, S. Beljakowa, M. Krieger, and T. Kimoto, Phys. Status Solidi A 206, 2374 (2009).

${ }^{9}$ A. Poggi, F. Moscatelli, S. Solmi, A. Armigliato, L. Belsito, and R. Nipoti, J. Appl. Phys. 107, 044506 (2010).

${ }^{10}$ K. McDonald, R. A. Weller, S. T. Pantelides, L. C. Feldman, G. Y. Chung, C. C. Tin, and J. R. Williams, J. Appl. Phys. 93, 2719 (2003).

${ }^{11}$ J. Rozen, S. Dhar, M. E. Zvanut, J. R. Williams, and L. C. Feldman, J. Appl. Phys. 105, 124506 (2009).

${ }^{12}$ T. Kimoto, Y. Kanzaki, M. Noborio, H. Kawano, and H. Matsunami, Jpn. J. Appl. Phys. 44, 1213 (2005).

${ }^{13}$ D. Okamoto, H. Yano, K. Hirata, T. Hatayama, and T. Fuyuki, IEEE Electron Device Lett. 31, 710 (2010).

${ }^{14}$ R. Kosugi, S. Suzuki, M. Okamoto, S. Harada, J. Senzaki, and K. Fukuda, IEEE Electron Device Lett. 23, 136 (2002).

${ }^{15}$ G. Gudjónsson, H. Ö. Ólafsson, F. Allerstam, P.-A. Nilsson, E. Ö. Sveinbjörnsson, H. Zirath, T. Rödle, and R. Jos, IEEE Electron Device Lett. 26, 96 (2005).

${ }^{16}$ H. Matsunami and T. Kimoto, Mater. Sci. Eng. R20, 125 (1997).

${ }^{17}$ K. McDonald, L. C. Feldman, R. A. Weller, G. Y. Chung, C. C. Tin, and J. R. Williams, J. Appl. Phys. 93, 2257 (2003).

${ }^{18}$ V. V. Afanas'ev, A. Stesmans, F. Ciobanu, G. Pensl, K. Y. Cheong, and S. Dimitrijev, Appl. Phys. Lett. 82, 568 (2003).

${ }^{19}$ I. Pintilie, C. M. Teodorescu, F. Moscatelli, R. Nipoti, A. Poggi, S. Solmi, L. S. Lovlie, and B. G. Svensson, J. Appl. Phys. 108, 024503 (2010).

${ }^{20}$ A. F. Basile, J. Rozen, J. R. Williams, L. C. Feldman, and P. M. Mooney, J. Appl. Phys. 109, 064514 (2011).

${ }^{21}$ V. Tilak, K. Matocha, and G. Dunne, IEEE Trans. Electron Devices 54, 2823 (2007).

${ }^{22}$ Y. Wang, K. Tang, T. Khan, M. K. Balasubramanian, H. Naik, W. Wang, and T. P. Chow, IEEE Trans. Electron Devices 55, 2046 (2008).

${ }^{23}$ S. Dhar, S. Haney, L. Cheng, S.-R. Ryu, A. K. Agarwal, L. C. Yu, and K. P. Cheung, J. Appl. Phys. 108, 054509 (2010).

${ }^{24}$ S. Dhar, X. D. Chen, P. M. Mooney, J. R. Williams, and L. C. Feldman, Appl. Phys. Lett. 92, 102112 (2008).

${ }^{25}$ H. Yoshioka, T. Nakamura, and T. Kimoto, J. Appl. Phys. 111, 014502 (2012).

${ }^{26}$ E. H. Nicollian and J. R. Brews, MOS Physics and Technology (Wiley, New York, 1982).

${ }^{27}$ Defects in Microelectronic Materials and Devices, edited by D. M. Fleetwood, S. T. Pantelides, and R. D. Schrimpf, (CRC, Boca Raton, 2009), Chap. 20.

${ }^{28}$ P. Zhao, Rusli, Y. Liu, C. C. Tin, W. G. Zhu, and J. Ahn, Microelectron. Eng. 83, 61 (2006).

${ }^{29}$ E. Bano, T. Ouisse, L. D. Cioccio, and S. Karmann, Appl. Phys. Lett. 65, 2723 (1994).

${ }^{30}$ W. Götz, A. Schöner, G. Pensl, W. Suttrop, W. J. Choyke, R. Stein, and S. Leibenzeder, J. Appl. Phys. 73, 3332 (1993).

${ }^{31}$ T. Kimoto, A. Itoh, H. Matsunami, S. Sridhara, L. L. Clemen, R. P. Devaty, W. J. Choyke, T. Dalibor, C. Peppermüller, and G. Pensl, Appl. Phys. Lett. 67, 2833 (1995).

${ }^{32}$ V. V. Afanas'ev, A. Stesmans, M. Bassler, G. Pensl, and M. J. Schulz, Appl. Phys. Lett. 76, 336 (2000).

${ }^{33}$ T. E. Rudenko, I. N. Osiyuk, I. P. Tyagulski, H. Ö. Ólafsson, and E. Ö. Sveinbjörnsson, Solid-State Electron. 49, 545 (2005).

${ }^{34}$ T. Umeda, K. Esaki, R. Kosugi, K. Fukuda, T. Ohshima, N. Morishita, and J. Isoya, Appl. Phys. Lett. 99, 142105 (2011).

${ }^{35}$ L. J. Kroko and A. G. Milnes, Solid-State Electron. 9, 1125 (1966).

${ }^{36}$ P. Tanner, S. Dimitrijev, H.-F. Li, D. Sweatman, K. E. Prince, and H. B. Harrison, J. Electron. Mater. 28, 109 (1999). 